(2) Open Access Full Text Article

REVIEW

\title{
A novel platinum chromium everolimus-eluting stent for the treatment of coronary artery disease
}

\author{
Johan Bennett \\ Christophe Dubois \\ Department of Cardiovascular \\ Diseases, University Hospitals Leuven, \\ Leuven, Belgium
}

This article was published in the following Dove Press journal:

Biologics:Targets and Therapy

18 June 2013

Number of times this article has been viewed

\begin{abstract}
The development of coronary stents represents a major step forward in the treatment of obstructive coronary artery disease since the introduction of percutaneous coronary intervention. The initial enthusiasm for bare metal stents was, however, tempered by a significant incidence of in-stent restenosis, the manifestation of excessive neointima hyperplasia within the stented vessel segment, ultimately leading to target vessel revascularization. Later, drug-eluting stents, with controlled local release of antiproliferative agents, consistently reduced this need for repeat revascularization. In turn, the long-term safety of first-generation drug-eluting stents was brought into question with the observation of an increased incidence of late stent thrombosis, often presenting as myocardial infarction or sudden death. Since then, new drugs, polymers, and platforms for drug elution have been developed to improve stent safety and preserve efficacy. Development of a novel platinum chromium alloy with high radial strength and high radiopacity has enabled the design of a new, thin-strut, flexible, and highly trackable stent platform, while simultaneously improving stent visibility. Significant advances in polymer coating, serving as a drug carrier on the stent surface, and in antiproliferative agent technology have further improved the safety and clinical performance of newer-generation drug-eluting stents. This review will provide an overview of the novel platinum chromium everolimus-eluting stents that are currently available. The clinical data from major clinical trials with these devices will be summarized and put into perspective.
\end{abstract}

Keywords: drug-eluting stent, restenosis, Promus Element, Synergy

\section{Introduction}

Coronary artery disease (CAD) is the leading cause of death worldwide, contributing to over 7.2 million deaths annually. ${ }^{1}$ Although CAD mortality rates have declined over the past three decades, CAD remains responsible for about one-third of all deaths in individuals over the age of 35 years. ${ }^{2}$ It has been estimated that nearly one-half of all middle-aged men and one-third of middle-aged women in the United States will develop some manifestation of CAD. ${ }^{3}$ In addition to medical treatment, percutaneous coronary intervention (PCI) is, for many patients, the management of choice for coronary atherosclerosis.

\section{Percutaneous coronary intervention}

Since the introduction of percutaneous balloon angioplasty by Gruntzig in 1977, major advances have been made in the clinical practice of PCI for the treatment of CAD. Puel and Sigwart, in 1986, deployed the first coronary stent to act as a scaffold, thus preventing vessel closure during PCI and reducing the incidence of restenosis, which was occurring 
in up to $40 \%$ of cases. ${ }^{4}$ Bare metal stents (BMS), however, were still associated with a $20 \%$ to $30 \%$ intra-stent restenosis rate requiring reintervention. ${ }^{5,6}$ Such restenosis occurred as a result of neointimal hyperplasia within the stent, caused by the migration and proliferation of vascular smooth muscle cells and intercellular matrix. Typically, this phenomenon is clinically evident within the first 6 to 9 months after stent placement, and occurs in response to strut-associated vascular injury and inflammation. ${ }^{5}$

In 2002, drug-eluting stents (DES) were introduced as a strategy to minimize restenosis, thus reducing the requirement for re-intervention. By releasing antiproliferative and antiinflammatory drugs directly into the vessel wall, DES inhibit the development of neointimal hyperplasia. Furthermore, the local release of the drug at the site of vascular injury achieves an effective local concentration of a drug for a certain period of time, while simultaneously avoiding systemic toxicity.

Initial animal studies demonstrated a clear benefit of DES over BMS (4\% to $6 \%$ restenosis rate versus $20 \%$ to $30 \%$ ), and pooled analyses of early randomized clinical trials further confirmed a $74 \%$ reduction in the risk of target lesion revascularization (TLR) at 1 year after stent implantation, favoring first-generation DES over BMS. ${ }^{7}$

The initial enthusiasm generated by controlled neointimal growth in DES was, however, tempered by reports on incomplete endothelialization and stent thrombosis. ${ }^{8}$ Animal studies demonstrated complete endothelialization with BMS at 28 days, whereas DES uniformly showed incomplete healing at 180 days. ${ }^{9}$ These observations led to the recommendation to use prolonged dual antiplatelet therapy (DAPT, aspirin and thienopyridine for at least 3-12 months) after DES, followed by lifelong aspirin monotherapy. ${ }^{10}$ Despite this regimen, late stent thrombosis (ie, occurring $>30$ days post stent insertion) remained a significant complication in patients with firstgeneration DES, in part influenced by stent characteristics, procedural aspects, and preexisting comorbidities which further increase the risk of stent thrombosis. ${ }^{11}$

The dramatic clinical consequences of stent thrombosis with increased risk for myocardial infarction and death have therefore shifted stent research towards enhanced safety and efficacy by optimally combining stent platform, drug, and kinetics of drug release.

\section{Newer-generation DES: analysis of DES compounds}

\section{Stent platform}

Important developments in stent platform, including design, structure, and composition, have resulted in significant technical advances and clinical benefits. The ideal stent is considered one that is highly deliverable, has a thin-strut, low-profile flexible design with high radiopacity, high radial strength, and minimal recoil. ${ }^{12}$

For many years, stents utilized 316L stainless steel (SS), owing to its excellent combination of mechanical properties, corrosion resistance, and biocompatibility. Reduction of strut thickness (130-140 $\mu \mathrm{m})$ further improved flexibility and trackability, while maintaining radial strength and minimal recoil, ultimately leading to improved stent deliverability and reduced restenosis rates. ${ }^{13}$ This occurred, however, at a cost of reduced stent visibility. Highly radiopaque gold surface coatings were initially explored to improve stent visibility, but resulted in poor clinical performance with higher rates of restenosis. ${ }^{14}$ Furthermore, given the relatively moderate yield strength of $316 \mathrm{~L}-\mathrm{SS}$, further opportunity for reduction of $316 \mathrm{~L}-\mathrm{SS}$ strut thickness was limited due to stent compression strength compromise, pointing towards the need for higher strength metal alloys.

Cobalt chromium $(\mathrm{CoCr})$ alloys enabled a reduction in strut thickness to around 80-90 $\mu \mathrm{m}$ with modest improvement in radiopacity (eg, density of $9.1 \mathrm{~g} / \mathrm{cm}^{3}$ and $8.4 \mathrm{~g} / \mathrm{cm}^{3}$ for the CoCr L605 Vision stent [Abbott Vascular, Santa Clara, CA, USA] and MP35N Driver stent [Medtronic, Minneapolis, MN, USA], respectively, compared with $8.0 \mathrm{~g} / \mathrm{cm}^{3}$ for $316 \mathrm{~L}-\mathrm{SS}$ ). Higher elastic properties of $\mathrm{CoCr}$, however, occur at a cost of greater recoil when compared with SS stents. ${ }^{15}$

Platinum $(\mathrm{Pt})$ represented an appealing alloy compound, given its known biocompatibility, chemical stability, corrosion resistance, and strength. Alloys with 33\% Pt appeared to provide the optimal balance between processability, mechanical properties, strength, stability, and radiopacity (density $9.9 \mathrm{~g} / \mathrm{cm}^{3}$ ).

Finally, an alloy combining $\mathrm{Pt}$ and $\mathrm{Cr}$ resulted in a significant yield in strength (480 $\mathrm{MPa})$ as compared with 316L-SS (275 MPa), enabling a reduction in strut thickness while maintaining radial strength, simultaneously providing improved radiopacity compared to the $316 \mathrm{~L}-\mathrm{SS}$ and $\mathrm{CoCr}$ alloys.$^{15}$

\section{Drug}

The antiproliferative agents used for the platforms of DES are highly lipophilic molecules that are distributed into the arterial wall and exert either immunosuppressive effects or antiproliferative effects on smooth muscle cells. Firstgeneration DES used sirolimus or paclitaxel as antiproliferative agents. Sirolimus, and its limus-family analogs, 
bind to the intracellular receptor FKBP12, inhibiting the mammalian target of rapamycin, resulting in up-regulation of cyclin-dependent kinase inhibitor p27Kip1. This blocks the proliferation of smooth-muscle cells in the gap $1\left(\mathrm{G}_{1}\right)$ phase of the cell cycle (immunosuppressive effects). Conversely, paclitaxel binds to the $\beta$-tubulin subunit of microtubules, inhibiting the disassembly of microtubules and thereby arresting cell replication in the $\mathrm{G}_{0}-\mathrm{G}_{1}$ and mitotic phases of the cycle of smooth-muscle cells (antiproliferative effects). Both sirolimus- and paclitaxel-eluting stents (SES and PES) significantly reduced the rate of repeat revascularization as compared with BMS, but several studies reported an increased risk of late and very late stent thrombosis with these DES. ${ }^{16}$ In an effort to enhance the safety and efficacy of DES, newer-generation stents eluting almost invariably limus analogs were developed. In large randomized trials, these everolimus-, zotarolimus- and biolimus-eluting stents (EES, ZES, and BES) showed improved clinical outcomes as compared to PES and SES, either with regard to the risk for death, myocardial infarction (MI) or repeat revascularization, and/or with regard to stent thrombosis. ${ }^{17-23}$

\section{Kinetics of drug release}

The antirestenotic efficacy of DES technology is based on the local delivery and modulated release to the vessel wall of cytotoxic drugs targeted at inhibition of neointimal hyperplasia. Control of drug release kinetics is a critical component of device efficacy. Many methods of loading stents with drugs have been developed for DES. Most of the agents must be bonded to a matrix polymer, which acts as a reservoir to ensure uniform distribution of the drug on the stent and drug retention during its insertion and deployment. The types, compositions, and designs of the polymers coated on the stent dictate the kinetics of drug release over a period of weeks to months following implantation. To date, this has been most effectively performed by stent coatings composed of synthetic nonerodable (permanent) polymer, such as poly-n-butyl methacrylate and polyethylene-venyl acetate with sirolimus and a poly(styrene-b-isobutylene-b-styrene) copolymer with PES, facilitating drug loading and delaying elution of the active drug. ${ }^{24}$ Polymer remaining after drug release is, however, an unnecessary design component of DES. Furthermore, first-generation permanent polymers have been associated with hypersensitivity reactions, delayed healing, and incomplete endothelialization that may contribute to an increased risk of late and very late stent thrombosis when compared to BMS. ${ }^{25-27}$ Consequently, current American and European clinical guidelines recommend at least 6 to
12 months of DAPT with aspirin and a thienopyridine to prevent late thrombotic complications after treatment with DES. ${ }^{28,29}$ Prolonged DAPT carries, though, not only inherent risks to the patient due to increased bleeding, especially with the newer and more potent antiplatelet drugs, but also raises a number of concerns regarding patient compliance, implications of DAPT interruption for invasive procedures, and economic cost of prolonged medication therapy.

In view of these valid concerns, extensive research has been directed toward modifying stent polymers with the aim of improving DES safety. Attempts have been made to reduce the total mass of polymer on the stent (eg, polymer thickness of $12.6 \mu \mathrm{m}$ for the first-generation Cypher vs $7.0 \mu \mathrm{m}$ for the Promus Element). In some designs, polymer mass is further reduced by selectively applying it to the abluminal stent surface, allowing targeted drug elution to the lumen endothelium while reducing the polymer-blood interface. Other modifications to first-generation DES have been an improved polymer biocompatibility and variable drugelution time windows (from 14 days for the Endeavour ZES to 90 days for the Promus Element EES, as compared with 120 days for the Cypher SES).

Finally, there is ongoing research into the development of biodegradable polymer coatings that offer the attractive prospect of controlled drug release without the potential for late polymer-associated adverse effects. To date, there have been conflicting results, ${ }^{30-32}$ although recent pooled analyses suggest a significant reduction of thrombosis risk at 4 years post stent implantation ${ }^{33}$ and a significant reduction in $\mathrm{TLR}^{34}$ in patients treated with biodegradable polymer DES. Ultimately, an alternative to avoid polymer issues is the development of novel polymer-free DES, such as the Cre8 polymer-free DES (CID, Saluggia, Italy), which employs an abluminal reservoir technology with specially formulated sirolimus loaded into the reservoirs, and the polymer-free drug-filled stent (Medtronic; 2013, data on file). The results of early preclinical and, in the case of Cre8 DES, clinical trials of these novel polymer-free DES are promising, although results from larger clinical trials are awaited. ${ }^{35}$

\section{Design structure of the platinum chromium EES}

\section{Platinum chromium (PtCr) Element stent platform}

The Element stent was designed utilizing the improved mechanical properties and radiopacity of the platinumenhanced alloy. The stent platform consists of 33\% iron, $33 \%$ platinum, $18 \%$ chromium, $9 \%$ nickel, $3 \%$ molybdenum, and a trace of manganese. It is laser cut from a tube of $\mathrm{PtCr}$ 
alloy, followed by an electrolytic etch to remove oxides and dross. Electropolishing is then carried out in phosphoric acid solution to yield a smooth, rounded, dimensionally uniform, chromium oxide-rich surface to help optimize biocompatibility. Finally a nitric passivation is performed. The biocompatibility has been validated in a variety of porcine implant studies. ${ }^{15}$

The strut thickness is $81 \mu \mathrm{m}$, with a portfolio of stents being developed in diameters ranging from $2.25 \mathrm{~mm}$ to $4.0 \mathrm{~mm}$ and lengths from $8 \mathrm{~mm}$ to $38 \mathrm{~mm}$. Key design objectives for the Element stent were improved flexibility and conformability (the ability of a stent to take up the natural curvature of a vessel without inducing vessel straightening or hinge points). Therefore, the Element stent was designed as a series of serpentine segments each joined to the next by two connectors, with the connector geometry arranged in a three-dimensional double helix-type configuration (Figure 1). This design allows forces to be balanced along the stent and allows each segment to operate almost independently of the others. The segment peaks are offset (nested), thereby reducing potential strut-to-strut contact when maneuvering the stent around a bend, enhancing deliverability. Furthermore, the peaks are widened and the length of each segment has been shortened to help redirect expansion strain longitudinally (contributing to increased radial strength) and to further improve conformability, respectively. Four separate stent models, including a specific $2.25 \mathrm{~mm}$ diameter model for smaller vessels, were developed to enhance the scaffolding and ensure adequate surface-to-artery ratio (which relates to uniformity of drug delivery). Most other contemporary stents are based on two stent models mounted on different-sized stent delivery balloons.

The mechanical characteristics and dimensions of the balloon and delivery system contribute to the overall

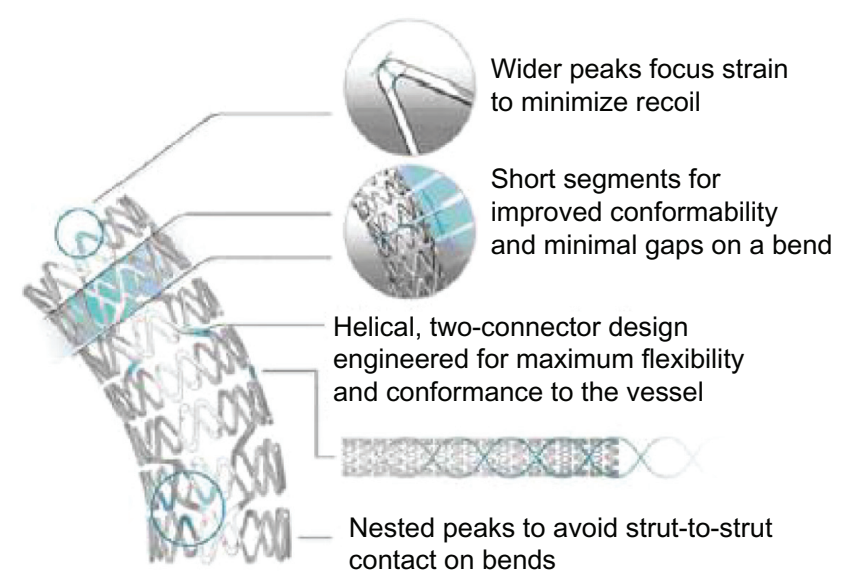

Figure I Design structure of the Promus Element stent. device deliverability and therefore are clinically relevant. The Element platform is mounted on a customized stent delivery system based on the Apex balloon catheter (Boston Scientific, Natick, MA, USA), providing improved proximal shaft pushability and distal shaft and balloon flexibility. The Promus Element Plus (Boston Scientific), commercially available from late 2012, is identical to the Promus Element apart from the incorporation of latest balloon delivery technology. This new delivery system consists of a new dual-layer balloon, a strong outer layer, and a flexible inner layer, resulting in overall improved deliverability. The Promus Premier (Boston Scientific), which will become commercially available in the near future, is identical to the Promus Element Plus but includes extra connectors on the proximal two segments of the stent. This latest platform enhancement will make the proximal stent end more robust to provide increased axial strength.

\section{Everolimus: drug pharmacology}

Everolimus (SDZ-RAD, $\mathrm{C}_{53} \mathrm{H}_{83} \mathrm{NO}_{14}$ ) is an analog of rapamycin, and is being successfully used in the prevention of allograft rejection after organ transplantation. The antiproliferative and immunosuppressive actions of everolimus are mediated by binding to its intracellular receptor, FKBP12. ${ }^{36,37}$ This everolimus-FKBP12 complex then interferes with FRAP (FKBP12-rapamycin-associated protein), a regulatory protein that controls, through the phosphorylation of $\mathrm{p} 70$ S6 kinase and 4E-BP1, cell metabolism and proliferation. ${ }^{38}$ Consequently, FRAP inhibition arrests cell cycle at the late $\mathrm{G}_{1}$ stage, leading to inhibition of cell metabolism, growth, and proliferation. Everolimus acts on several cell types, including vascular smooth muscle cells, and in experimental models has been shown to significantly reduce neointimal proliferation following stent implantation. ${ }^{39}$ More recently, another unique property of everolimus has been reported in an animal atherosclerotic model of coronary stenting: stentbased delivery of everolimus was found to selectively clear macrophages in rabbit atherosclerotic plaques by autophagy, a mammalian target of rapamycin inhibition-dependent and novel mechanism to induce cell death in mammalian cells. ${ }^{40}$ Due to its molecular and chemical structure, everolimus is more lipophilic than sirolimus and is more rapidly absorbed into the arterial wall, therefore potentially enhancing the speed of action and depth of absorption following stent implantation. ${ }^{41}$

Extensive clinical data support the safety and efficacy of everolimus for stent drug elution. Indeed, the Xience V (Abbott Vascular) and Promus (Boston Scientific) EES, two identical 
EES on a balloon-expandable Multi-Link vision L-605 Co-Cr platform, were shown in randomized trials to reduce the rates of angiographic and clinical restenosis, $\mathrm{MI}$, and stent thrombosis compared with a PES. ${ }^{17,18,42}$ More recent meta-analyses have reported lower risks of stent thrombosis, TLR, and MI associated with EES relative to other available DES. ${ }^{20,43,44}$

\section{Promus Element $\mathrm{PtCr}$ everolimus-eluting stent}

The Promus Element consists of the newly developed Element stent platform that is coated with a polymer (total polymer thickness of $7 \mu \mathrm{m}$ ) with two layers, a poly n-butyl methacrylate primer layer and a nonadhesive, durable, biocompatible drug matrix layer. The drug matrix is composed of a copolymer of polyvinylidene fluoride and hexafluoropropylene blended with everolimus. This matrix of everolimus fluoropolymer contains $100 \mu \mathrm{g}$ of everolimus per square centimeter of stent surface area and is designed to release approximately $80 \%$ of the drug within 30 days after implantation in vivo, with none detectable after 120 days, and with minimal everolimus systemic levels. The fluoropolymer surface elicits a biological response known as fluoropassivation that minimizes the fibrin deposition and thrombogenicity, thereby reducing the inflammatory reaction and enhancing endothelial healing. ${ }^{45,46}$ This polymer-drug combination is identical to the combination incorporated in the Promus/Xience V CoCr EES stent (Boston Scientific/ Abbott Vascular) mentioned previously. Hence, the Promus Element PtCr EES is a combination of the successful Promus/ Xience V drug and polymer formulation with a PtCr stent platform designed for improved deliverability and radiopacity, and with high radial strength. The Promus Element PtCr-EES received CE mark approval and was launched in Europe and other international markets in 2009, with FDA approval in 2012.

\section{Synergy PtCr everolimus-eluting stent}

The most recent addition to the family of PtCr EES is the Synergy stent (Boston Scientific). It consists of a thinner-strut platinum chromium stent platform that delivers everolimus from an ultrathin $(4 \mu \mathrm{m})$ bioabsorbable poly-DL-lactide-coglycolide (PLGA) polymer applied to the outer (abluminal) stent surface only (Figure 2).

The Synergy stent underwent several modifications to the Promus Element PtCr platform, including reduced strut thickness $(74 \mu \mathrm{m})$ with rounder struts, changes in connector angle, presence of two additional proximal and distal end connectors (to reduce the risk of longitudinal stent distortion, see below), and changes in peak radius (Figure 2). These modifications

A
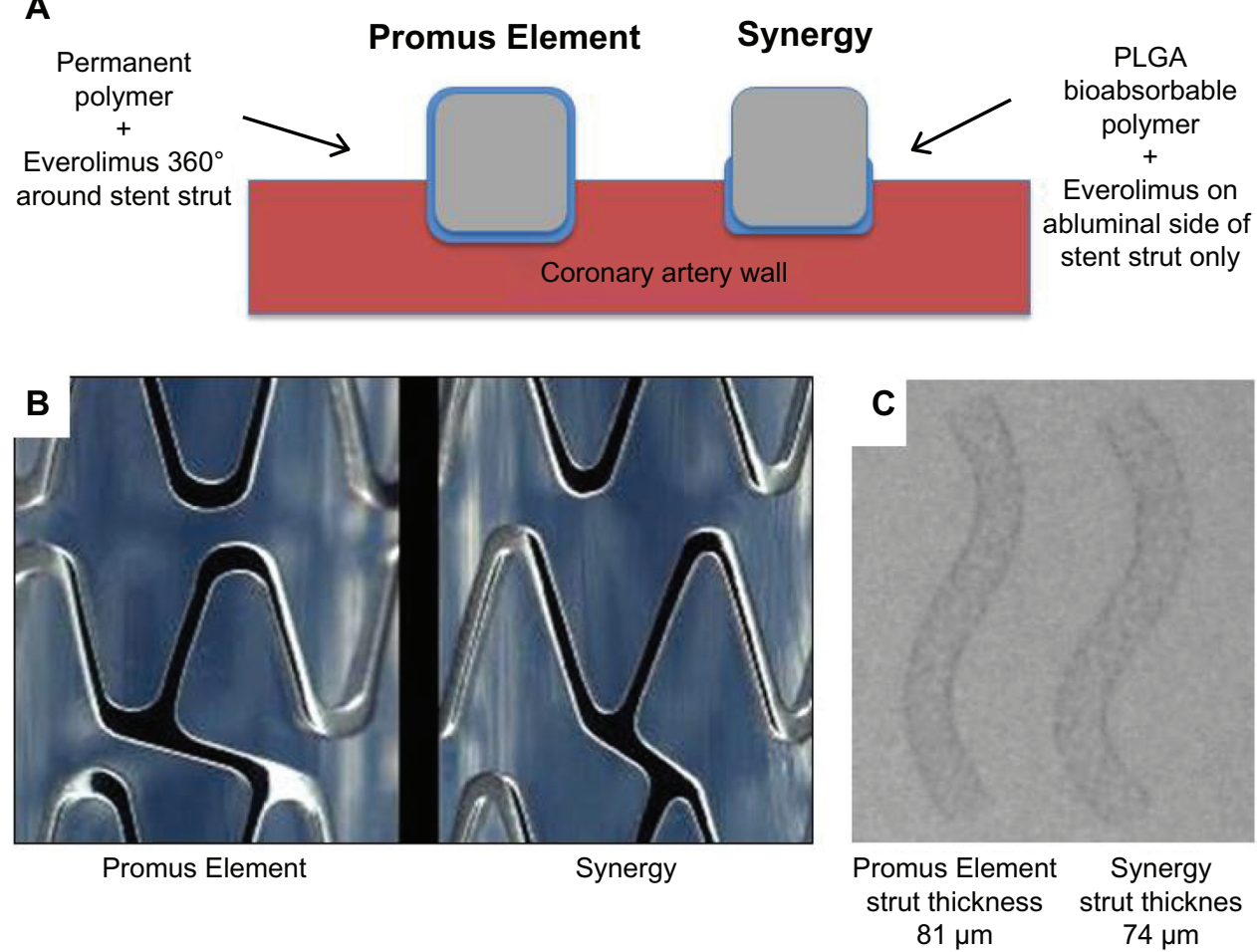

Figure 2 Key differences between the Promus Element and Synergy stent. In the thinner-strut Synergy stent, the drug and bioabsorbable poly-DL-lactide-co-glycolide (PLGA) polymer are applied to the abluminal stent surface only (A). The Synergy stent has different strut thickness, connector angle, and peak radius diameters, resulting in an enhanced stent platform (B). Panel (C) shows similar radiopacity between the stents despite reduced strut thickness in the Synergy stent. 
are intended to improve the crimping profile, flexibility, conformability, and longitudinal robustness.

Like the Promus Element Plus, the Synergy stent makes use of the latest balloon delivery technology with a duallayer balloon.

In contrast with the majority of currently available DES, dosage and duration of polymer have been reduced with Synergy by limiting the polymer coating exclusively to the abluminal stent surface, and introducing bioabsorbable polymer formulations. The ultrathin $(4 \mu \mathrm{m})$, light $(200 \mu \mathrm{g}$ per $16 \mathrm{~mm}$ stent vs $>400 \mu \mathrm{g}$ per $16 \mathrm{~mm}$ stent for all other DES) bioabsorbable polymer of the Synergy stent allows complete endothelialization within 28 days of implantation in a porcine coronary artery model and completion of polymer reabsorption within 4 months (Figure 3 ). ${ }^{47}$ The polymer is therefore gone when it is no longer needed, shortly after completion of drug elution, minimizing polymer exposure in the vessel. In theory, the Synergy may thus reduce the risk of stent thrombosis and minimize the requirement for prolonged DAPT. The Synergy stent received CE approval in October 2012.

\section{Efficacy and safety studies}

\section{PLATINUM Promus Element Clinical Trial Program}

The PLATINUM Clinical Trial Program was established to assess the efficacy and safety of the Promus PtCr EES in five multicenter studies totaling more than 1800 patients. These studies included a pivotal randomized controlled trial (RCT) in workhorse lesions, and single-arm studies evaluating small vessels, long lesions, quantitative coronary angiography (QCA), and intravascular ultrasound data, and finally a pharmacokinetic study (Table 1).
The PLATINUM RCT is a prospective, multicenter, singleblind trial designed to evaluate the safety and efficacy of the Promus Element stent in the treatment of patients with up to two de novo coronary lesions. ${ }^{48}$ A total of 1530 patients were randomized 1:1 to treatment with either Promus/XienceV CoCr-EES or Promus Element PtCr-EES. The primary endpoint was the 12-month rate of target lesion failure (TLF), defined as target vessel-related cardiac death, target vessel-related MI, or ischemia-driven TLR. At 12 months, the Promus Element EES was noninferior to the Promus EES for TLF (3.4\% vs $2.9 \%$, $P=0.001$ for noninferiority). Similarly, in the intention-to-treat population, the 12-month rate of TLF was not significantly different between the Promus Element and the Promus EES (3.5\% vs 3.2\%, respectively; HR [95\% CI] $=1.12[0.64,1.95])$. There were no significant differences between the Promus Element and the Promus/XienceV in the 12-month rates of cardiac death $(0.9 \%$ vs $0.7 \%, P=0.58)$, MI $(1.1 \%$ vs $1.8 \%, P=0.25)$, TLR (both $1.9 \%, P=0.96$ ), and definite or probable stent thrombosis (both $0.4 \% P=1.00$ ). A higher rate of unplanned stenting (9.8\% vs 5.9\%, $P=0.004)$ attributable to inadequate lesion coverage (ie, "geographical miss"; $3.4 \%$ vs $1.4 \%, P=0.01$ ) was observed with Promus/XienceV EES compared with Promus Element EES. In a post hoc analysis, the rate of TLR and TLF were significantly lower between 1-2 years in patients treated with the PtCr-EES compared to CoCr-EES. ${ }^{49}$

After completion of the PLATINUM workhorse RCT, patients with prespecified lesion subsets were separately treated with the $2.25 \mathrm{~mm}$ small vessel (SV) or $38 \mathrm{~mm}$ long lesion (LL) Promus Element EES in the single-arm PLATINUM SV and LL studies. In these studies, outcome after treatment with the PtCR EES was compared to a

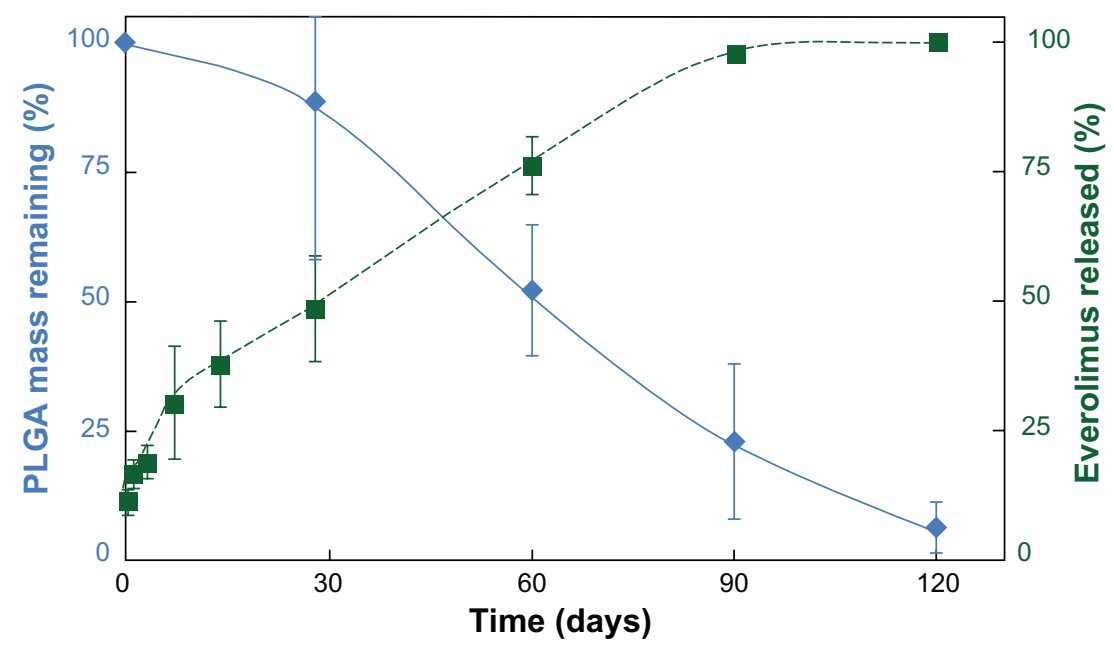

Figure 3 Kinetics of drug release and polymer absorption with the Synergy stent.

Note: The Synergy Stent shows drug release over 90-120 days, concurrent with polymer absorption.

Abbreviation: PLGA, poly-DL-lactide-co-glycolide. 
Table I PLATINUM and EVOLVE Clinical Trial Programs

\begin{tabular}{|c|c|c|c|c|c|c|c|}
\hline Study & Design & Lesion type & $\begin{array}{l}\text { Lesion } \\
\text { length }\end{array}$ & $\begin{array}{l}\text { Baseline } \\
\text { RVD }\end{array}$ & Control & $I^{\circ}$ Endpoint & $\begin{array}{l}\text { Patients } \\
\mathbf{N}^{\circ}\end{array}$ \\
\hline $\begin{array}{l}\text { PLATINUM } \\
\text { QCA }\end{array}$ & $\begin{array}{l}\text { Prospective multicenter } \\
\text { single-arm }\end{array}$ & De novo & $\leq 34 \mathrm{~mm}$ & $\begin{array}{l}\geq 2.25 \text { to } \\
\leq 4.25 \mathrm{~mm}\end{array}$ & $\begin{array}{l}\text { Historical results } \\
\text { Taxus Express }\end{array}$ & $\begin{array}{l}\text { 30-day TLF } \\
\text { 9-month in-stent LLL }\end{array}$ & 100 \\
\hline $\begin{array}{l}\text { PLATINUM } \\
\text { RCT }\end{array}$ & $\begin{array}{l}\text { Prospective multicenter } \\
\text { single-blind randomized }\end{array}$ & $\begin{array}{l}\text { De novo } \\
\text { ( } \leq 2 \text { lesions) }\end{array}$ & $\leq 24 \mathrm{~mm}$ & $\begin{array}{l}\geq 2.5 \text { to } \\
\leq 4.25 \mathrm{~mm}\end{array}$ & $\begin{array}{l}\text { CoCr-EES } \\
\text { (XienceV or Promus) }\end{array}$ & I2-month TLF & 1,530 \\
\hline $\begin{array}{l}\text { PLATINUM } \\
\text { SV }\end{array}$ & $\begin{array}{l}\text { Prospective multicenter } \\
\text { single-arm }\end{array}$ & De novo & $\leq 28 \mathrm{~mm}$ & $\begin{array}{l}\geq 2.25 \text { to } \\
<2.50 \mathrm{~mm}\end{array}$ & $\begin{array}{l}\text { Historical results } \\
\text { Taxus Express }\end{array}$ & I2-month TLF & 94 \\
\hline $\begin{array}{l}\text { PLATINUM } \\
\text { LL }\end{array}$ & $\begin{array}{l}\text { Prospective multicenter } \\
\text { single-arm }\end{array}$ & De novo & $24-34 \mathrm{~mm}$ & $\begin{array}{l}\geq 2.50 \text { to } \\
\leq 4.25 \mathrm{~mm}\end{array}$ & $\begin{array}{l}\text { Historical results } \\
\text { Taxus Express }\end{array}$ & I2-month TLF & 102 \\
\hline $\begin{array}{l}\text { PLATINUM } \\
\text { PK }\end{array}$ & $\begin{array}{l}\text { Prospective multicenter } \\
\text { single-arm }\end{array}$ & De novo & $\leq 24 \mathrm{~mm}$ & $\begin{array}{l}\geq 2.5 \text { to } \\
\leq 4.25 \mathrm{~mm}\end{array}$ & $\mathrm{~N} / \mathrm{A}$ & Observational & 20 \\
\hline $\begin{array}{l}\text { EVOLVE } \\
\text { FHU }\end{array}$ & $\begin{array}{l}\text { Prospective multicenter } \\
\text { single-blind randomized }\end{array}$ & De novo & $\leq 28 \mathrm{~mm}$ & $\begin{array}{l}\geq 2.25 \text { to } \\
\leq 3.5 \mathrm{~mm}\end{array}$ & $\begin{array}{l}\text { PtCr-EES } \\
\text { (Promus Element) }\end{array}$ & $\begin{array}{l}\text { 30-day rate of TLF } \\
\text { 6-month in-stent LLL }\end{array}$ & 291 \\
\hline $\begin{array}{l}\text { EVOLVE II } \\
\text { RCT }\end{array}$ & $\begin{array}{l}\text { Prospective multicenter } \\
\text { single-blind randomized }\end{array}$ & $\begin{array}{l}\text { De novo ( } \leq 3 \text { lesions; } \\
\leq 2 \text { vessels) }\end{array}$ & $\leq 34 \mathrm{~mm}$ & $\begin{array}{l}\geq 2.25 \text { to } \\
\leq 4.0 \mathrm{~mm}\end{array}$ & $\begin{array}{l}\text { PtCr-EES } \\
\text { (Promus Element plus) }\end{array}$ & I2-month TLF & 1,684 \\
\hline $\begin{array}{l}\text { EVOLVE II } \\
\text { PK }\end{array}$ & $\begin{array}{l}\text { Prospective multicenter } \\
\text { single-arm }\end{array}$ & $\begin{array}{l}\text { De novo ( } \leq 3 \text { lesions; } \\
\leq 2 \text { vessels) }\end{array}$ & $\leq 34 \mathrm{~mm}$ & $\begin{array}{l}\geq 2.25 \text { to } \\
\leq 4.0 \mathrm{~mm}\end{array}$ & N/A & Observational & $20-30$ \\
\hline $\begin{array}{l}\text { EVOLVE II } \\
\text { DM }\end{array}$ & $\begin{array}{l}\text { Prospective multicenter } \\
\text { single-arm }\end{array}$ & $\begin{array}{l}\text { De novo ( } \leq 3 \text { lesions; } \\
\leq 2 \text { vessels) }\end{array}$ & $\leq 34 \mathrm{~mm}$ & $\begin{array}{l}\geq 2.25 \text { to } \\
\leq 4.0 \mathrm{~mm}\end{array}$ & $\mathrm{~N} / \mathrm{A}$ & I2-month TLF & $250-292$ \\
\hline $\begin{array}{l}\text { EVOLVE } \\
\text { QCA }\end{array}$ & Prospective multicenter & De novo & $\leq 34 \mathrm{~mm}$ & $\begin{array}{l}\geq 2.25 \text { to } \\
\leq 4.0 \mathrm{~mm}\end{array}$ & N/A & 9-month in-stent LL & 100 \\
\hline
\end{tabular}

Abbreviations: RVD, reference vessel diameter; QCA, quantitative coronary angiography; TLF, target lesion failure (defined as the composite of target vessel-related cardiac death, target vessel-related myocardial infarction, or ischaemia-driven target lesion revascularization); RCT, randomized control trial; SV, small vessel; LL, long lesion; PK, pharmacokinetic; FHU, first human use; DM, diabetes mellitus; LLL, late luminal loss; CoCr-EES, cobalt chromium everolimus-eluting stent; PtCr-EES, platinum chromium everolimus-eluting stent; N/A, not available.

prespecified performance goal based on outcomes from patients treated with the $2.25 \mathrm{~mm}$ SV or $38 \mathrm{~mm}$ LL TAXUS Express PES in the TAXUS V study. ${ }^{50}$

Ninety-four patients with coronary lesions in a vessel segment with reference diameter of $2.25 \mathrm{~mm}$ to $<2.5 \mathrm{~mm}$ and $\leq 28 \mathrm{~mm}$ in length were included in the PLATINUM SV study. One-year TLF rates with the $2.25 \mathrm{~mm}$ PtCr-EES were significantly lower than the predetermined performance goals with TAXUS Express $(2.4 \%$ vs $21.1 \%, P<0.001)$. Furthermore, this 1-year TLF rate compared favorably with outcomes observed with the ION (Taxus Element) PES in the PERSEUS small vessel study (4.7\%), ${ }^{51}$ the XienceV EES in the SPIRIT small vessel study (5.1\%), ${ }^{52}$ and with the Biomatrix Flex BES in the small vessel analysis from the LEADERS trial $(9.6 \%))^{53}$ Furthermore, no stent thromboses were seen with the SV PtCr-EES through 2 years of follow-up. ${ }^{54}$

One hundred and two patients with coronary artery lesions between $24 \mathrm{~mm}$ and $34 \mathrm{~mm}$ long in vessels of $2.50-4.25 \mathrm{~mm}$ in diameter were treated with the $38 \mathrm{~mm}$ PtCrEES in the PLATINUM LL study. At 1 year, TLF rate with the PtCr-EES was significantly lower than the predetermined performance goals $(3.2 \%$ vs $19.4 \%$ for TAXUS Express, $P<0.001)$. The TLF rate observed at 1 year with the $38 \mathrm{~mm}$ PtCr-EES in this study is consistent with published rates for contemporary DES in long lesions, $(2.4 \%$ for the SES and
$7.2 \%$ for the PES in the LONG DES II study). ${ }^{55}$ No stent thromboses were observed with the LL PtCr-EES through 2 years of follow-up..$^{54}$

The PLATINUM QCA substudy is a single arm trial designed to examine angiographic and intravascular ultrasound (IVUS) outcomes with the PtCr-EES in 100 patients. The 30-day primary endpoint (cardiac death, MI, TLR, or definite and probable stent thrombosis) occurred in $1.0 \%$ of patients, with no additional major clinical events through 1 year. The efficacy endpoint of angiographic in-stent late luminal loss at 9 months with PtCr EES $(0.17 \pm 0.25 \mathrm{~mm})$ was comparable with that previously reported for the Xience V/Promus EES (CoCr-EES) in the SPIRIT First, ${ }^{56}$ SPIRIT II,${ }^{57}$ and SPIRIT III ${ }^{42}$ trials. By IVUS, the percentage of volume obstruction with PtCr EES at 9 month follow-up was 7\%, equally in line with CoCr EES in the SPIRIT trials. Postprocedure incomplete stent apposition, as assessed with IVUS, appeared to be less frequent for the PtCr-EES (5.7\%) than that reported for Xience V/Promus EES (34.4\%) in SPIRIT III. Although this may reflect an advantageous stent design, it could also be related to other factors, including the extensive (90.1\%) use of postdilatation and/or the maximum postdilatation pressure $(18.0 \pm 3.6 \mathrm{~atm})$ in PLATINUM QCA. ${ }^{58}$

Finally, the PLATINUM pharmacokinetic trial (PK) is a single-arm trial evaluating the PK profile of $24 \mathrm{~mm}$ Promus 
Element stents in 22 subjects with de novo coronary lesions. In this study, the highest blood concentration of everolimus remained well below the therapeutic range used for sustained treatment of subjects to inhibit organ rejection, and declined rapidly in all subjects, with no detectable drug level at 24 hours (Boston Scientific, data on file).

Overall, the clinical efficacy and safety outcomes observed in the PLATINUM Clinical Trial Program support the use of the PtCr-EES in the treatment of workhorse coronary lesions, as well as in the treatment of small caliber vessels and long lesions, confirming the successful transfer of favorable outcomes associated with everolimus to the novel PtCr stent design (Figure 4).

\section{EVOLVE Synergy clinical trial program}

Over 2000 patients are planned to be treated in the EVOLVE clinical trial program to assess the safety and efficacy of the PtCr Synergy EES. The program includes the EVOLVE First Human Use (FHU) study, the EVOLVE II study (currently recruiting), and future studies involving EVOLVE QCA, EVOLVE China, and EVOLVE short DAPT (Table 1).

The EVOLVE FHU study compares safety and efficacy of two dose formulations of the Synergy stent, with abluminal bioresorbable polymer coating, to the durable polymer Promus Element EES. ${ }^{59}$ As the safety and efficacy of lower doses of everolimus were previously not investigated,

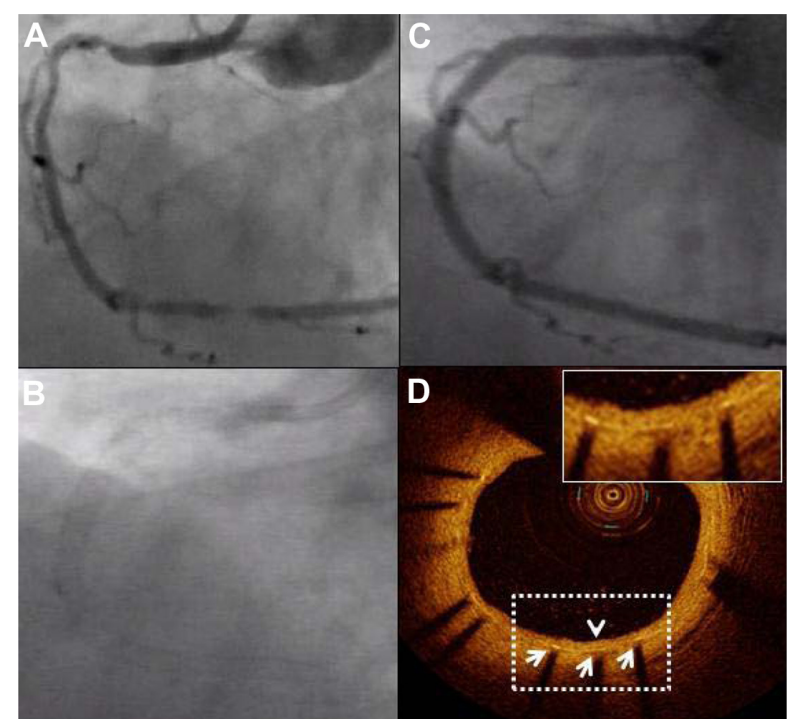

Figure 4 Coronary angiography and optical coherence tomography (OCT) 9 months after Promus Element implantation. A diffusely diseased right coronary artery (A) was treated with three slightly overlapping Promus Element stents. Panel (B) confirms excellent radiopacity of the Platinum Chromium Element stent platform. Follow-up angiography at 9 months shows prolonged vessel patency (C). A representative OCT image confirms favorable healing: all struts (white arrows) are covered with a thin homogeneous layer of neointimal tissue (arrowhead) with a well-preserved lumen area (D). the EVOLVE FHU trial evaluated one formulation of the Synergy stent with total everolimus dose similar to that of the currently available EES (38 $\mu \mathrm{g}$ to $179 \mu \mathrm{g}$, depending on stent length) and a second formulation with half the dose of everolimus (19 $\mu \mathrm{g}$ to $90 \mu \mathrm{g}$, depending on stent length) to determine if comparable efficacy could be achieved with a lower and potentially safer drug dose. A total of 291 patients with de novo coronary lesions were enrolled in this study, a prospective, randomized, single-blind noninferiority trial. Patients were randomized in a 1:1:1 ratio to Synergy, Synergy half dose, or Promus Element. The primary clinical endpoint was the 30-day rate of TLF, defined as cardiac death or MI related to the target vessel, or TLR. The primary angiographic endpoint was in-stent late luminal loss measured by QCA at 6 months after implantation. TLF occurred at 30 days in $1.1 \%(n=1)$ in the Synergy group and $3.1 \%(n=3)$ in the Synergy half dose group, compared with no events with Promus Element. At 6 months, the incidence of TLF was $1.1 \%, 4.1 \%$, and $3.1 \%$, respectively, with secondary 6-month endpoint TLR rates of $1.1 \%, 1.0 \%$, and 3.1\%. Both dose formulations of the Synergy stent were noninferior to Promus Element with regards to angiographic in-stent late luminal loss at 6 months $(0.10 \pm 0.25 \mathrm{~mm}, 0.13 \pm 0.26 \mathrm{~mm}$, and $0.15 \pm 0.34 \mathrm{~mm}$, respectively). Furthermore, 12-month efficacy and safety data were favorable, with no significant difference in clinical endpoints, including TLF, death, MI and TLR between the 3 groups, confirming the positive clinical performance for the Synergy stent. ${ }^{60}$

The pivotal EVOLVE II project, consisting mainly of a multicenter noninferiority RCT, commenced recruitment in November 2012. The aim of this study is to further assess the safety and effectiveness of the Synergy stent for the treatment coronary lesions in 1684 patients in up to 160 worldwide sites. Patients will be randomized 1:1 to the Synergy versus the Promus Element Plus EES. The primary end-point is TLF at 12 months. Complete follow-up will be for 5 years. The EVOLVE II project will equally involve a concurrent PK substudy (20-30 patients) as well as a consecutive diabetes single-arm registry (250-292 patients).

The EVOLVE clinical trial program will be completed with an additional QCA study, a specific trial for China, and a study to explore the potential shorter need for DAPT with Synergy, based on the bioabsorbable properties of the polymer used for this stent.

\section{Pt Cr stents and longitudinal stent deformation}

Longitudinal stent deformation (LSD) is a recently recognized complication of coronary stent deployment, 
but mechanisms contributing to its occurrence and associated clinical outcomes remain unclear. LSD consists of any longitudinal compression or elongation of a stent resulting in the need for additional treatment, including repeat dilatation of the stent, placement of a second stent, and/or surgical intervention. To date, several published case series ${ }^{61,62}$ and a more recent retrospective review of the FDA MAUDE database for device malfunctions ${ }^{63}$ have highlighted this new phenomenon. However, it remains difficult to draw firm conclusions on mechanisms and procedural and anatomical factors that predispose to this complication based on these cases. Recent engineering analyses have suggested that there are significant differences in longitudinal strength between contemporary stent platforms. ${ }^{64,65}$

At least 8 stent designs have been implicated, although LSD appears to occur more often with the Promus Element stent ( 7 out of 12 cases published). As the Promus Element stent is the only stent with $\mathrm{Pt}-\mathrm{Cr}$ alloy, its radiopacity is much higher, favoring earlier angiographic detection of a given LSD with Promus Element as compared with other stent types. There is no reason to think that the Pt-Cr alloy itself could be responsible for mechanical differences. In fact, Pt-Cr has a superior density and tensile strength compared with $\mathrm{Co}-\mathrm{Cr}$ and $316 \mathrm{~L} .{ }^{15}$ The mechanical susceptibility to longitudinal compression of the Promus Element is therefore only dependent on its unique design, an offset peak-to-peak design, and only two connectors between each stent ring. In response to these concerns, the recently developed Synergy PtCr-EES and Promus Premier PtCr-EES have additional end connectors to increase the longitudinal robustness.

Finally, an independent angiographic core laboratory systematically analyzed 2403 stents implanted in the PLATINUM and PERSEUS randomized trials. Interestingly, across the three distinct coronary stent platforms with differing metal alloy composition (316L SS, CoCr, PtCr), strut thickness $(132 \mu \mathrm{m}, 81 \mu \mathrm{m})$ and stent designs, no incidence of severe stent deformation was identified. ${ }^{66}$ Of note, the present study included only 513 ACC/AHA type C lesions ( $21 \%$ of all lesions), the type in which LSD is most likely to occur. Lesions with complex characteristics such as severe calcification, severe tortuosity, ostial lesions, and chronic total occlusions were excluded in these trials. Further study of the relative frequency of LSD of different stents is thus warranted in larger studies of highly complex lesions. In the meantime, strategies to avoid LSD have been suggested and include adequate target lesion preparation, more optimal stent expansion with the stent delivery system, minimized guide catheter-stent contact during efforts to maximize guide catheter support, and use of finesse and not force if resistance upon recrossing is met.

\section{Conclusion}

The novel thin strut PtCr coronary everolimus-eluting stents combine improved acute mechanical performance in terms of flexibility, deliverability, conformability, radial strength, and visibility, with favorable long-term clinical results. Several large trials have demonstrated the safety and efficacy of the Promus Element PtCr EES, with incidences of TLF and stent thrombosis at 1 year as low as $3 \%$ and $0.4 \%$, respectively. Furthermore, initial clinical experience with the improved thinner strut Synergy PtCr stent with abluminal everolimuselution through a bioabsorbable polymer coating looks promising, potentially paving the way towards reduced duration of DAPT therapy. The challenge remaining for these novel DES is to further confirm their value in a real-world setting of complex patients and interventions.

\section{Disclosure}

The authors report no conflicts of interest in this work. $\mathrm{CD}$ has received institutional grants from Abbott Vascular, Medtronic, Biosensors International, and Boston Scientific. $\mathrm{CD}$ is a member of the Scientific Medical Advisory Board of Boston Scientific.

\section{References}

1. The World Health Organization. The top ten causes of death fact sheet. 2004. Available at: http://www.who.int/mediacentre/factsheets/fs310/ en/index.html. Accessed January 18, 2013.

2. Lloyd-Jones D, Adams RJ, Brown TM, et al. Executive summary: heart disease and stroke statistics - 2010 update: a report from the American Heart Association. Circulation. 2010;121(7):948-954.

3. Lioyd-Jones DM, Larson MG, Beiser A, Levy D. Lifetime risk of developing coronary heart disease. Lancet 1999;353(9147):89-92.

4. Serruys PW, Kutryk MJ, Ong ATL. Coronary-artery stents. $N$ Engl $J$ Med. 2006;354(5):483-495.

5. Moliterno DJ. Healing Achilles - sirolimus versus paclitaxel. $N$ Engl J Med. 2005;353(7):724-727.

6. Arjomand H, Turi Z, McCormick D, Goldberg S. Percutaneous coronary intervention: historical perspectives, current status, and future direction. Am Heart J. 2003;146(5):787-796.

7. Hill RA, Dundar Y, Bakhai A, Dickson R, Walley T. Drug-eluting stents: an early systematic review to inform policy. Eur Heart $J$. 2004;25(11):902-919.

8. McFadden EP, Stabile E, Regar E, et al. Late thrombosis in drug-eluting coronary stents after discontinuation of antiplatelet therapy. Lancet. 2004;364(9444):1519-1521.

9. Tsimikas S. Drug-eluting stents and late adverse clinical outcomes: lessons learned, lessons awaited. J Am Coll Cardiol. 2006;47(10):2112-2115.

10. Silber S, Albertsson P, Aviles FF, et al. Guidelines for percutaneous interventions. The task force for percutaneous coronary interventions of the European Society of Cardiology. Eur Heart J. 2005;26(8):804-847.

11. Iakovou I, Schmidt $\mathrm{T}$, Bonizzoni E, et al. Incidence, predictors, and outcome of thrombosis after successful implantation of drug-eluting stents. JAMA. 2005;293(17):2126-2130. 
12. Menown IB, Noad R, Garcia EJ, Meredith I. The platinum chromium element stent platform: from alloy, to design, to clinical practice. $A d v$ Ther. 2010;27(3):129-141.

13. Kastrati A, Mehilli J, Dirschinger J, et al. Intracoronay stenting and angiographic results: strut thickness effect on restenosis outcome (ISAR-STEREO) trial. Circulation. 2001;103(23):2816-2821.

14. Kastrati A, Schomig A, Dirschinger J, et al. Increased risk of restenosis after placement of gold-coated stents. Circulation. 2000;101(21):2478-2483.

15. O'Brien BJ, Stinson JS, Larsen SR, Eppihimer MJ, Carroll WM. A platinum-chromium steel for cardiovascular events. Biomaterials. 2010;31(14):3755-3761.

16. Stettler C, Wandel S, Allemann S, et al. Outcomes associated with drugeluting and bare-metal stents: a collaborative network meta-analysis. Lancet. 2007;370(9591):937-948.

17. Kedhi E, Joesoef KS, McFadden E, et al. Second-generation everolimus-eluting and paclitaxel-eluting stents in real-life practice (COMPARE): a randomised trial. Lancet. 2010;375(9710):201-209.

18. Stone GW, Rizvi A, Newman W, et al. Everolimus-eluting versus paclitaxel-eluting stents in coronary artery disease. $N$ Engl $J$ Med. 2010;362(18):1663-1674.

19. Jensen LO, Thayssen P, Hansen HS, et al. Randomized comparison of everolimus-eluting and sirolimus-eluting stents in patients treated with percutaneous coronary intervention: the Scandinavian Organization for Randomized Trials with Clinical Outcome IV (SORT OUT IV). Circulation. 2012;125(10):1246-1255.

20. Bangalore S, Kumar S, Fusaro M, et al. Short- and long-term outcomes with drug-eluting and bare-metal coronary stents: a mixed-treatment comparison analysis of 117762 patient-years of follow-up from randomized trials. Circulation. 2012;125(23):2873-2891.

21. Camenzind E, Wijns W, Mauri L, et al. Stent thrombosis and major clinical events at 3 years after zotarolimus-eluting or sirolimus-eluting coronary stent implantation: a randomised, multicentre, open-label, controlled trial. Lancet. 2012;380(9851):1396-1405.

22. Leon MB, Nikolsky E, Cutlip DE, et al. Improved late clinical safety with zotarolimus-eluting stents compared with paclitaxel-eluting stents in patients with de novo coronary lesions: 3-year follow-up from the ENDEAVOR IV (Randomized Comparison of Zotarolimus- and Paclitaxel-Eluting Stents in Patients With Coronary Artery Disease) trial. JACC Cardiovasc Interv. 2010;3(10):1043-1050.

23. Serruys P, Buszman P, Linke A, et al. 5-year follow-up from a prospective, randomized trial of biolimus A9-eluting stents with a biodegradable polymer vs sirolimus-eluting stents with a durable polymer-final report of the LEADERS study [abstract]. J Am Coll Cardiol. 2012; 60(Suppl 17):B13-B14.

24. Rogers CD. Optimal stent design for drug delivery. Rev Cardiovasc Med. 2004;5(Suppl 2):S9-S15.

25. Kotani J, Awata M, Nanto S, et al. Incomplete neointimal coverage of sirolimus-eluting stents: angioscopic findings. $\mathrm{J} \mathrm{Am} \mathrm{Coll} \mathrm{Cardiol.}$ 2006;47(10):2108-2111.

26. Finn AV, Joner M, Nakazawa G, et al. Pathological correlates of late drug-eluting stent thrombosis: strut coverage as a marker of endothelialization. Circulation. 2007;115(8):2435-2441.

27. Daemen J, Wenaweser P, Tsuchida K, et al. Early and late stent thrombosis of sirolimus-eluting and paclitaxel-eluting stents in routine clinical practice: data from a large two-institutional cohort study. Lancet. 2007;369(9562):667-678.

28. King SB 3rd, Smith SC Jr, Hirshfeld JW Jr, et al. 2007 focused update of the ACC/AHA/SCAI 2005 guideline update for percutaneous coronary intervention: a report of the American College of Cardiology/American Heart Association Task Force on Practice guidelines. J Am Coll Cardiol. 2008;51(2):172-209.

29. Task Force on Myocardial Revascularization of the European Society of Cardiology (ESC) and the European Association for Cardio-Thoracic Surgery (EACTS); European Association for Percutaneous Cardiovascular Interventions (EAPCI), Wijns W, Kolh P, Danchin N, et al. Guidelines on myocardial revascularization. Eur Heart J. 2010;31(20): 2501-2555.
30. Windecker S, Serruys PW, Wandel S, et al. Biolimus-eluting stent with biodegradable polymer versus sirolimus-eluting stent with durable polymer for coronary revascularisation (LEADERS): a randomised non-inferiority trial. Lancet. 2008;372(9644):1163-1173.

31. Krucoff MW, Kereiakes DJ, Petersen JL, et al. A novel bioresorbable polymer paclitaxel-eluting stent for the treatment of single and multivessel coronary disease: primary results of the COSTAR (Cobalt Chromium Stent With Antiproliferative for Restenosis) II study. $J$ Am Coll Cardiol. 2008;51(16):1543-1552.

32. Grube E, Schofer J, Hauptmann KE, et al. Novel paclitaxel-eluting stent with an ultrathin abluminal biodegradable polymer 9-month outcomes with the JACTAX HD stent. JACC Cardiovasc Interv. 2010;3(4):431-438.

33. Stefanini GG, Byrne RA, Serruys PW, et al. Biodegradable polymer drug-eluting stents reduce the risk of stent thrombosis at 4 years in patients undergoing percutaneous coronary intervention: a pooled analysis of individual patient data from the ISAR-TEST 3, ISARTEST 4, and LEADERS randomized trials. Eur Heart J. 2012;33(10): 1214-1222.

34. Lupi A, Rognoni A, Secco GG, et al. Biodegradable versus durable polymer drug eluting stents in coronary artery disease: Insights from a meta-analysis of 5834 patients. Eur J Prev Cardiol. 2013. [Epub November 14, 2012.]

35. Carrie D, Berland B, Verheye S, et al. A multicenter randomized trial comparing amphilimus- with paclitaxel-eluting stents in de novo native coronary artery lesions. J Am Coll Cardiol. 2012; 59(15):1371-1376.

36. Schuler W, Sedrani R, Cottens S, et al. SDZ RAD, a new rapamycin derivative: pharmacological properties in vitro and in vivo. Transplantation. 1997;64(1):36-42.

37. Marx SO, Marks AR. Bench to bedside: the development of rapamycin and its application to stent restenosis. Circulation. 2001;104(8): 852-855.

38. Carter AJ. TOR of the cell cycle: Are there important implications for diabetics in the era of the drug-eluting stent? Catheter Cardiovasc Interv. 2004;61(2):233-236.

39. Waksman R, Pakala R, Baffour R, et al. Optimal dosing and duration of oral everolimus to inhibit in-stent neointimal growth in rabbit iliac arteries. Cardiovasc Revasc Med. 2006;7(3):179-184.

40. Verheye S, Martinet W, Kockx MM, et al. Selective clearance of macrophages in atherosclerotic plaques by autophagy. $\mathrm{J} \mathrm{Am} \mathrm{Coll} \mathrm{Cardiol}$. 2007;49(6):706-715.

41. Kahan BD, Wong RL, Carter C, et al. A phase I study of a 4-week course of SDZ-RAD (RAD) quiescent cyclosporine-prednisone-treated renal transplant recipients. Transplantation. 1999;68(8):1100-1106.

42. Stone GW, Midei M, Newman W, et al. Comparison of an everolimus-eluting stent and a paclitaxel-eluting stent in patients with coronary artery disease: a randomized trial. JAMA. 2008;299(16): 1903-1913.

43. Baber U, Mehran R, Sharma SK, et al. Impact of the everolimus-eluting stent on stent thrombosis: a meta-analysis of 13 randomized trials. $\mathrm{JAm}$ Coll Cardiol. 2011;58(15):1569-1577.

44. Palmerini T, Kirtane AJ, Serruys PW, et al. Stent thrombosis with everolimus-eluting stents: meta-analysis of comparative randomized controlled trials. Circ Cardiovasc Interv. 2012;5(3):357-364.

45. Xie X, Guidoin R, Nutley M, Zhang Z. Fluoropassivation and gelatin sealing of polyester arterial prostheses to skip preclotting and constrain the chronic inflammatory response. J Biomed Mater Res B Appl Biomater. 2010;93(2):497-509.

46. Gutiérrez-Chico JL, van Geuns RJ, Regar E, et al. Tissue coverage of a hydrophilic polymer-coated zotarolimus-eluting stent vs a fluoropolymer-coated everolimus-eluting stent at 13-month follow-up: an optical coherence tomography substudy from the RESOLUTE All Comers trial. Eur Heart J. 2011;32(19):2454-2463.

47. Chen Y-L, Foss A, Eppihimer M, et al. Characterization of in vivo poly(dl-lactic-co-glycolic acid) bioabsorption from a drug-eluting stent. EuroIntervention. 2012;8(Suppl N):N043. 
48. Stone GW, Teirstein PS, Meredith IT, et al. A prospective randomized evaluation of a novel everolimus-eluting stent: the PLATINUM (a prospective, randomized, multicenter trial to assess an everlimuseluting coronary stent system [Promus Element] for the treatment of up to two de novo coronary artery lesions) trial. J Am Coll Cardiol. 2011;57(16):1700-1708.

49. Stone GW, Teirstein PS, Meredith IT, et al. Two-year results of the PLATINUM randomized trial comparing platinum chromium promus element and cobalt chromium PROMUS/XIENCE V everolimus-eluting stents in de novo coronary artery lesions. J Am Coll Cardiol. 2012; 59(13 Suppl 1):E323.

50. Stone GW, Ellis SG, Cannon L, et al. Comparison of a polymer-based paclitaxel-eluting stent with a bare metal stent in patients with complex coronary artery disease: a randomized controlled trial. JAMA 2005;294(10):1215-1223.

51. Cannon L, Kereiakes DJ, Mann T, et al. A prospective evaluation of the safety and efficacy of TAXUS Element paclitaxel-eluting coronary stent implantation for the treatment of de novo coronary artery lesions in small vessels: The PERSEUS Small Vessel Trial. EuroIntervention. 2011;6(8):920-927.

52. Cannon LA, Simon DI, Kereiakes D, et al. The XIENCE nano everolimus eluting coronary stent system for the treatment of small coronary arteries: The SPIRIT small vessel trial. Catheter Cardiovasc Interv. 2012;80(4):546-553.

53. Wykrzykowska JJ, Serruys PW, Onuma Y, et al. Impact of vessel size on angiographic and clinical outcomes of revascularization with biolimuseluting stent with biodegradable polymer and sirolimus-eluting stent with durable polymer, the LEADERS trial substudy. JACC Cardiovasc Interv. 2009;2(9):861-870.

54. Meredith I, Teirstein P, Stone G, et al. Two-year results of the PLATINUM small vessel trial: evaluation of a $2.25 \mathrm{~mm}$ platinum chromium everolimus-eluting stent in de novo coronary artery lesions. EuroIntervention. 2012;8(Suppl N):N161

55. Kim YH, Park SW, Lee SW, et al. Sirolimus-eluting stent versus paclitaxel-eluting stent for patients with long coronary artery disease. Circulation. 2006;114(20):2148-2153.

56. Serruys PW, Ong AT, Piek JJ, et al. A randomized comparison of a durable polymer Everolimus-eluting stent with a bare metal coronary stent: The SPIRIT first trial. EuroIntervention. 2005;1(1):58-65.
57. Serruys PW, Ruygrok P, Neuzner J, et al. A randomised comparison of an everolimus-eluting coronary stent with a paclitaxel-eluting coronary stent: the SPIRIT II trial. EuroIntervention. 2006;2(3):286-294.

58. Meredith IT, Whitbourn R, Scott D, et al. PLATINUM QCA: a prospective, multicentre study assessing clinical, angiographic, and intravascular ultrasound outcomes with the novel platinum chromium thin-strut PROMUS Element everolimus-eluting stent in de novo coronary stenoses. EuroIntervention. 2011;7(1):84-90.

59. Meredith IT, Verheye S, Dubois CL, et al. Primary endpoint results of the EVOLVE trial: a randomized evaluation of a novel bioabsorbable polymer-coated, everolimus-eluting coronary stent. J Am Coll Cardiol. 2012;59(15):1362-1370.

60. Verheye S, Meredith IT, Weissman NJ, et al. Six-month IVUS and 12-month clinical outcomes in the EVOLVE FHU trial: a randomised evaluation of a novel bioabsorbable polymer-coated, everolimus-eluting stent. EuroIntervention. 2012;8(Suppl N):N42.

61. Hanratty CG, Walsh SJ. Longitudinal compression: a "new" complication with modern coronary stent platforms - time to think beyond deliverability? EuroIntervention. 2011;7(7):872-877.

62. Williams PD, Mamas MA, Morgan KP, et al. Longitudinal stent deformation: a retrospective analysis of frequency and mechanisms. EuroIntervention. 2012;8(2):267-274.

63. Mamas MA, Williams PD. Longitudinal stent deformation: insights on mechanisms, treatments and outcomes from the Food and Drug Administration Manufacturer and User Facility Device Experience database. EuroIntervention. 2012;8(2):196-204.

64. Prabhu S, Schikorr T, Mahmoud T, Jacobs J, Potgieter A, Simonton C. Engineering assessment of the longitudinal compression behaviour of contemporary coronary stents. EuroIntervention. 2012;8(2):275-281.

65. Ormiston JA, Webber B, Webster MW. Stent longitudinal integrity. bench insights into a clinical problem. JACC Cardiovasc Interv. 2011;4(12):1310-1317.

66. Kereiakes DJ, Popma JJ, Cannon LA, et al. Longitudinal stent deformation: quantitative coronary angiographic analysis from the PERSEUS and PLATINUM randomised controlled clinical trials. EuroIntervention. 2012;8(2):187-195.
Biologics: Targets \& Therapy

\section{Publish your work in this journal}

Biologics: Targets \& Therapy is an international, peer-reviewed journal focusing on the patho-physiological rationale for and clinical application of Biologic agents in the management of autoimmune diseases, cancers or other pathologies where a molecular target can be identified. This journal is indexed on PubMed Central, CAS, EMBase, Scopus

\section{Dovepress}

and the Elsevier Bibliographic databases. The manuscript management system is completely online and includes a very quick and fair peerreview system, which is all easy to use. Visit http://www.dovepress. $\mathrm{com} /$ testimonials.php to read real quotes from published authors. 